\title{
EVALUATION OF CHARACTER DISPLACEMENT AMONG PLANTS IN TWO TROPICAL POLLINATION GUILDS ${ }^{1}$
}

\author{
K. Greg Murray, ${ }^{2}$ Peter Feinsinger, and William H. Busby \\ Department of Zoology, University of Florida, Gainesville, Florida 32611 USA \\ YAN B. LINHART \\ Department of EPO Biology, Box 334, University of Colorado, Boulder, Colorado 80309 USA \\ AND \\ JAMES H. BEACH ${ }^{3}$ AND SHARON KINSMAN ${ }^{4}$ \\ Department of Zoology, University of Florida, Gainesville, Florida 32611 USA
}

\begin{abstract}
In cloud forest at Monteverde, Costa Rica, two guilds of bird-pollinated plants exist; one guild pollinated by long-billed hummingbirds, primarily the Green Hermit (Phaethornis guy), and one guild pollinated by short-billed hummingbirds, primarily the Purple-throated Mountain-gem (Lampornis calolaema). Plants were assigned to guilds based on hummingbird visit patterns documented during $>4000$ plant-hours of field observations, and on identities of pollen grains collected from 600 mist-netted hummingbirds. Other studies indicated that pollination in these plants is often insufficient for maximum seed set. Each guild was examined for character displacement expected within a stable assemblage of plants structured by competition for pollination. (1) By comparing observed flowering phenologies with those obtained through a randomization procedure, we determined whether each species' phenology minimized overlap with the remainder of its guild. (2) We also examined complementarity between phenological displacement and morphological displacement in reproductive structures.

Neither guild exhibited pronounced character displacement. (1) In most cases, flowering phenologies were indistinguishable from those generated at random; the few statistically significant departures mostly indicated aggregation, rather than displacement, of flowering seasons. (2) In most cases, morphological similarity was independent of phenological similarity. The only statistically significant result among the studied species was a positive correlation, among long-flowered species only, between rarity and uniqueness of flowering season.

We do not conclude that this absence of expected pattern indicates that competition never occurs or that competition is an inconsequential ecological event. Rather, we attribute absence of pattern to the following aspects of biological variability, two of which we have demonstrated in other studies. (1) Within any one year, density-dependent competition for pollination is sporadic, and is not clearly related to flowering season or morphological similarity. (2) The nature of interspecific interactions varies among years, as neither the relative intensities of flowering nor the flowering seasons themselves are consistent from year to year. (3) The nature of interspecific interactions varies with changes in species composition, which occur over short distances. (4) The assemblage of species is probably not stable over long time spans; the species have Gleasonian ecologies that change distribution and abundance faster than natural selection or diffuse competition can screen out improper phenotypes or species, respectively.
\end{abstract}

Key words: character displacement; cloud forest; competition for pollination; Costa Rica; flowering phenology; hummingbirds; null models; pollination.

\footnotetext{
'Manuscript received 28 April 1986; revised 10 November 1986; accepted 4 December 1986.

${ }^{2}$ Present address: Department of Biology, Hope College, Holland, Michigan 49423 USA.

${ }^{3}$ Present address: Bureau of Biological Research, Rutgers University, P.O. Box 1059, Piscataway, New Jersey 08854 USA.

${ }^{4}$ Present address: Department of Biology, Bates College, Lewiston, Maine 04240 USA.
}

\section{INTRODUCTION}

During the past decade, many ecologists have reexamined apparent patterns in the phenotypic traits of sympatric species, patterns attributed to ongoing ecological processes (Strong et al. 1984, Diamond and Case 1986). The patterns most often debated involve character displacement among species in a guild (sensu Root 1967) or "taxon-guild" (Schoener 1986). The 
process most often held responsible is interspecific competition for shared, limited resources (Connell 1983, Schoener 1983). Among groups of plants that share animal pollinators or seed dispersers, interspecific competition for the services of animals could lead to displacement in the timing of flowering or fruiting (reviewed by Rathcke and Lacey 1985, Wheelwright 1985). Among species that flower simultaneously, competition could result in morphological character displacement that involves flower shape or placement of reproductive parts (Heinrich 1975, Waser 1983).

Before causal relationships between an ecological process and an interspecific pattern are invoked, the existence of pattern should be conclusively demonstrated (Simberloff 1983). In the past, the existence of pattern within pollination guilds was sometimes judged only by a visual inspection of flowering seasons (e.g., Heithaus 1974, Stiles 1977, Feinsinger 1978). Recently, more objective statistical techniques have been used to evaluate pattern (Poole and Rathcke 1979, Pleasants 1980, 1983, Thomson 1980, 1981, Fleming and Partridge 1984, Wheelwright 1985). These techniques have been applied to data from both temperate and tropical plant assemblages. Although a few data sets suggest regular spacing of flowering or fruiting seasons, most indicate phenologies that are random or even aggregated relative to those generated by the null model (Waser 1983, Fleming and Partridge 1984, Rathcke and Lacey 1985, Wheelwright 1985, Kochmer and Handel 1986).

Most data sets used in previous analyses are somewhat inappropriate for rigorous statistical tests of character displacement within guilds (Fleming and Partridge 1984). First, data were often collected in a qualitative manner only, such that statistical analyses can deal only with the spacing of flowering or fruiting "peaks," or the spacing of the midpoints of periods of "good flower." As Zimmerman (1984) and others have pointed out, however, flowers produced away from peak times may be at least as important in seed production and plant population dynamics as flowers produced at peak times. In addition, the variable shapes of seasonal flowering curves among species (e.g., Gentry 1974, Bawa 1983) may be biologically meaningful, so that neither the timing of peak flowering alone nor the entire span of flowering alone is likely to estimate biologically important aspects of flowering for all species. Second, as Fleming and Partridge (1984) and Primack (1985) point out, many data sets include only a subset of the guild under study (e.g., Stiles 1975, 1977, Fleming 1985, Wheelwright 1985) or include representatives of several overlapping guilds (e.g., Parrish and Bazzaz 1979, Rabinowitz et al. 1981). Third, in many studies it is misleading to erect a null model of random flowering and an alternate hypothesis of regularly dispersed peaks (cf. Harvey et al. 1983). Pollinator abundance may vary widely over the season, for reasons unrelated to flower abundance, such that the process of competition alone would lead to aggregation, rather than regularity, in flowering peaks (Rathcke and Lacey 1985). In addition, abiotic factors may render some seasons (e.g., winter at temperate or boreal latitudes, severe dry seasons in many tropical regions) less suitable for flowering than others, so that the null model for tests of competitioninduced pattern should not necessarily be based on random flowering throughout the year (Stiles 1979, Cole 1981, Rathcke and Lacey 1985).

Much of the discussion of character displacement in flowering phenologies or other flowering traits involves hummingbird-pollinated plants (Heithaus 1974, Stiles 1977, 1979, 1981, 1985, Waser 1978a, Brown and Kodric-Brown 1979, Poole and Rathcke 1979, Waser and Real 1979, Cole 1981, Gleeson 1981, Fleming and Partridge 1984). In this paper we evaluate evidience for competition-induced pattern in two guilds of hummingbird-pollinated plants in cloud forest at Monteverde, Costa Rica. Plants were assigned to guilds objectively and without taxonomic limitations. We subjected quantitative phenological data collected over $2 \mathrm{yr}$ to randomization techniques similar to those of Fleming and Partridge (1984) and Kochmer and Handel (1986). Comparisons of data with a null model of random flowering are reasonable, because (1) population densities of the hummingbird pollinators are remarkably stable over the year, and (2) the constantly wet conditions of the cloud forest understory provided no a priori basis for expecting some seasons to be better for flowering than others.

\section{METHODS \\ Phenological data}

The Monteverde Cloud Forest Preserve, near Monteverde, Provincia de Puntarenas, Costa Rica, contains $\approx 4800$ ha of Lower Montane Rain Forest (Holdridge 1967) and similar life zones. Except for a single livestock trail and several footpaths, the Preserve has been influenced very little by human disturbance. The Preserve lacks exotic species except for a few ruderals restricted to the livestock trail. Although direct rainfall decreases from November to May, the trade winds that prevail during that season constantly bathe the cloud forest in which we worked with wind-blow mist. As a result, the forest interior never experiences a true "dry season." Lawton and Dryer (1980) provide details on climate and vegetation.

Phenological data were derived from monthly censuses of hummingbird-visited flowers. On the 1 st $d$ of each month from July 1981 through June 1983, we counted all bird-visited flowers on each of 10 study plots. Four plots located in closed-canopy, mature-phase forest ranged from 1600 to $1925 \mathrm{~m}^{2}$, totalling 7280 $\mathrm{m}^{2}$. Six plots, totalling $2300 \mathrm{~m}^{2}$, encompassed gaps caused by treefalls that had occurred 1-3 yr carlier; these ranged from 132 to $544 \mathrm{~m}^{2}$. Study plots are described in detail elsewhere (Feinsinger et al. 1987). 
We collected data by walking slowly along a grid of trails in each plot, carefully counting all open flowers of all plant species known to be visited by hummingbirds, up to $10 \mathrm{~m}$ above the forest floor. Because hummingbirds that frequent understory plants also forage at sevcral species of epiphytic Ericaceae in the canopy, one of us (Busby) collected data on ericad flowering using another method. One day each month, all fallen corollas of canopy and subcanopy Ericaceae known to be frequented by hummingbirds were counted along a $1.5 \times 5000 \mathrm{~m}$ belt transect located near the other study plots. Because cricad flowers remain on the plant for $\approx 2 \mathrm{~d}$, the number of fallen corollas should be proportional to the total number of viable flowers open the previous day. The number of freshly fallen flowers may underestimate the number of open ones; on the other hand, the corollas counted may actually have accumulated over several previous days, leading to overestimation. Because these methods differ radically from the censuses of open, viable flowers within study plots, we performed all analyses twice, once with data (including data on epiphytic Ericaceae within $10 \mathrm{~m}$ of, and visible from, the ground) obtained from the 10 study plots only, and once substituting the belt-transect Ericaceac data (corrected for area covered) for the Ericaceae data collected on plots.

\section{Analysis of phenological overlap}

At Monteverde, as elsewhere in the Neotropics, plants adapted for hummingbird pollination fall into two groups: those with long corollas, pollinated almost exclusively by long-billed hummingbirds such as most members of the hermit hummingbird subfamily (Phaethornithinac), and those with much shorter corollas, pollinated almost exclusively by hummingbirds with quite short, straight bills (Stiles 1981, Feinsinger 1983, Feinsinger et al. 1986). Based upon our familiarity with the system (4218 plant-hours of observations on hummingbird visits made during 1981-1982, and identification of $\approx 700000$ pollen grains collected from 600 hummingbirds mist-netted on study plots during 19811983), we could unequivocally assign nearly all species to one or the other guild. The few exceptions, plants visited frequently by both long- and short-billed hummingbirds, were sparsely flowering species whose inclusion in analyses for both guilds scarcely changed the results at all.

At long-flowered plants (including the few "ambivalent" species listed in Table 1), $68.2 \%$ of all pollinating visits came from a single hummingbird species, Phaethornis guy (the Green Hermit). Most remaining visits came from three other long-billed hummingbird species. At short-flowered plants adapted for hummingbird pollination, $96.9 \%$ of all pollinating visits came from Lampornis calolaema (the Purple-throated Mountaingem; Feinsinger et al. 1986). Thus, flowering plants in either guild experience collective effects of several other species, such that competitive or facilitative relation- ships among species within each guild should be diffuse rather than pairwise. If competition were to induce character displacement, for example, each species would be phenologically displaced from the summed flowering of all other species in its guild ("guildmates") rather than from one "competitor" species at a time. Therefore, following Thomson and Rusterholz (1982) and Fleming and Partridge (1984), instead of pairwise overlaps we computed $n$-wise overlaps, or the overlap between each species and the summed flowering of all its guildmates.

Our approach used a procedure similar to that of Fleming and Partridge (1984) to compare observed $n$-wise overlaps with those generated by a series of randomizations. Observed 24-mo flowering curves for all species were started at random months within the 24-mo period, "wrapping around" to the beginning of the period as necessary. This method is analogous to mapping the observed phenological curves onto a 24mo calendar at random. Overlap between each species and the summed phenology of all its guildmates was then computed using the proportional similarity index (symmetrical), or PS (Eq. 1), and the Levins (1968) index (asymmetrical), or $L I$ (Eq. 2).

$$
P S_{i j}=1-0.5\left(\sum_{m}\left|p_{i m}-p_{j m}\right|\right)
$$

and

$$
L I_{i j}=\sum_{m}\left(p_{i m} p_{j m}\right) / p_{i m}^{2},
$$

where $p_{i m}$ is the proportion of species $i$ 's flowering that occurs in month $m$, and $p_{j m}$ is the proportion of summed flowering by all of $i$ 's guildmates that occurs in month $m$. PS averages the overlap of $i$ on $j$ with that of $j$ on $i$, whereas $L I$ is the extent to which $i$ is overlapped by $j$. For each set of randomly generated phenologies, both indices were calculated for each species $i$ and the sum of its guildmates $(j)$; then another set of randomly generated phenologies was generated. The procedure was repeated 100 times for each guild, with (one set) or without (a second set) the data on canopy Ericaceae from the belt transect. For each overlap index in each of the four sets of 100 runs, then, we ranked overlap values in ascending order, and noted how many values from randomly generated phenologies were greater or less than the observed overlap between species $i$ and its combined guildmates $j$. To reject the null hypothesis of random flowering pattern, the observed overlap between species $i$ and its combined guildmates $j$ must be lower than that of $95 \%$ of the randomly generated values (indicating a divergent flowering season) or $>95 \%$ of the randomly generated values (indicating a convergent flowering season).

\section{Morphological data}

One response to competition for pollination might be divergence in the location of reproductive parts 


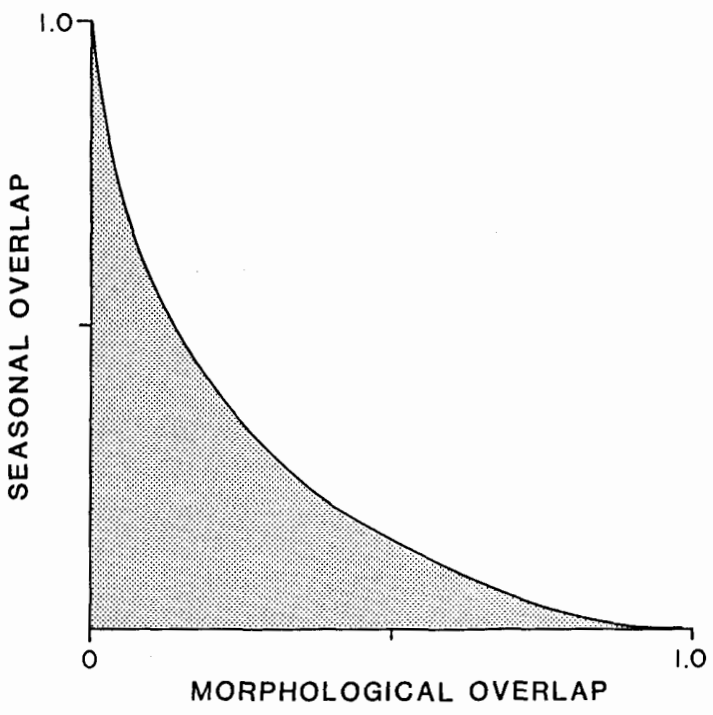

FIG. 1. A possible complementary relationship of phenological overlap to morphological overlap between pairs of plant species in the same guild. If competition has structured the guild, most species pairs would be expected to fall in the area below the curve.

among members of a guild. Such divergence would lessen the amount of pollen lost to inappropriate stigmas, or of inappropriate pollen deposited on stigmas, should pollinators visit a variety of simultaneously flowering species (Waser 1978b, Brown and KodricBrown 1979). For most species in both guilds, we measured distance from base of the flower (nectaries) to midpoint of anthers in a sample of at least 10 flowers taken from at least three plants. Data from 600 pollen loads taken from hummingbirds (P. Feinsinger, K. G. Murray, and C. A. Murcia, personal observation) indicate that the base-to-anthers distance is a reasonable estimate of the site where pollen is carried on hummingbirds, relative to the tip of the bill, even though loads on hummingbirds tend to be somewhat smeared and intermingled. For each species, we calculated mean and variance in base-to-anthers distance.

\section{Comparison of phenological and morphological overlap}

Morphological overlap between two guildmate plants is calculated as the area of intersection of the two frequency distributions of base-to-anther distances (cf. MacArthur 1972:42):

$$
\alpha=e^{-\frac{\left|\bar{x}_{1}{ }^{2}-\bar{x}_{2}{ }^{2}\right|}{\delta_{1}{ }^{2}-\delta_{2}{ }^{2}}} .
$$

If interspecific competition has exerted a strong force on community structure, then species pairs with high overlaps along both morphological and phenological dimensions should be scarce relative to pairs with low overlaps along one or both dimensions (Fig. 1). For pairs of species with low phenological overlap the ex- tent of morphological overlap should be irrelevant. Similarly, for pairs with low morphological overlap the extent of phenological overlap should be unimportant (at least in terms of interspecific pollen transfer-cf. Waser $1978 b, 1983)$. The particular overlap values we calculated may not always accurately represent the potential impact of plants on one another's pollination success; thus, the values themselves are not an issue, only the relative locations of the points relating morphological to phenological overlap.

We assessed complementarity of displacement within each guild in two ways. First, for each guild we plotted the point representing phenological overlap, measured with $P S$ (Eq. 1, with $j$ a single other species) against morphological overlap (Eq. 3) for each possible pair of species. This provides a large sample size, but the pairs are not statistically independent; furthermore, any trends could be obscured by adding species that overlap little with any guildmates to species that overlap greatly with all their guildmates. Thus, within each guild we also created a separate plot for the overlaps between a given species $i$ and each of its guilumates. On each plot, we divided the points into four quadrants using the method of Steele and Torrie (1960: 410), drawing a vertical line from the median $x$ value and a horizontal line from the median $y$ value. We then counted the points in the upper right-hand quadrant. A random dispersion of points (no complementarity) would, on average, provide the upper right quadrant with $1 / 4$ of the total; complementarity would produce a number much less than $1 / 4$ of the total (cf. Fig. 1). Using the corner test of association (Steele and Torrite 1960: 410), we examined the plot for each guild in total, and the separate plot for each long-flowered plant species. We had complete data on too few short-flowered species to test each separately for significance.

\section{RESULTS}

\section{Flowering phenologies}

Most hummingbird-pollinated plant species at Monteverde appear to flower independently of the times at which their guildmates flower. In Table 1 , numbers indicate the rank of observed overlap (Eqs. 1 and 2) relative to 100 randomly generated overlaps. Thus, values $<5$ indicate observed overlaps less than those generated by the null model, values $>95$ indicate observed overlaps greater than those generated by the random model. Although the symmetrical index (Eq. 1) and asymmetrical index (Eq. 2) generated somewhat different values, both lead to the same general conclusions. In the long-flower guild (Table 1A), only the understory epiphyte Guzmania nicaraguensis (visited by short-billed as well as long-billed hummingbirds) and the common giant herb Heliconia tortuosa flowered in patterns that, in most comparisons, minimized overlap with their guildmates. In contrast, in most comparisons four species (Poikilacanthus macranthus, 
Alloplectus tetragonus, Drymonia rubra, and Malvaviscus arboreus) each overlapped with remaining long flowers more than expected from the null model. In the short-flower guild (Table 1B), no species we examined appeared to minimize overlap with other species, whereas Burmeistera tenuiflora overlapped with the remaining short flowers more than expected.

No relationship existed between unusual overlaps and length of flowering season. For example, Guzmania and Poikilacanthus both had very short flowering seasons, whereas Heliconia, Drymonia, and Burmeistera all had lengthy seasons. Results from analyses incorporating the belt-transect Ericaceae data were qualitatively similar to those from analyses restricted to the data set collected on the principal study plots.

We also examined each guild for a relationship between displacement in flowering phenology and rarity, reasoning that rare species might suffer the most from interspecific competition (leading to the most unique flowering seasons) or benefit the most from facilitation (leading to the most aggregated flowering seasonsFeinsinger 1983, Rathcke 1983). We measured "uniqueness" of flowering season as the numbers reported for the Levins (1968) index in Table 1, and measured flowering density in a species as the sum of all flowers counted on the 24 monthly censuses. In the short-flower guild, no correlation existed between rank in uniqueness and rank in rarity $\left(r_{s}=-0.0018\right)$. In the long-flower guild, however, rare species tended to have more unique flowering peaks than common ones $\left(r_{s}=\right.$ $.5123, P<.05)$.

\section{Does morphological displacement complement phenological displacement?}

Morphological displacement among species with similar phenologies did not compensate for the general absence of significant divergence in flowering times (Table 2). In most plots of morphological overlap against phenological overlap, pairs with high overlap along both dimensions (upper right-hand quadrant) were not scarce relative to pairs in other quadrants, whether a guild was examined in its entirety or individual species were compared with all their guildmates. Typically (Fig. 2), morphological overlap values were independent from phenological overlap values. Two long-flowered species, Heliconia tortuosa and Columnea magnifica, actually experienced a greater number of high pairwise overlaps along both dimensions than expected by chance, whereas only one species, Malvaviscus palmanus, experienced a significant trade-off between phenological and morphological overlap. Because these are multiple tests, one $P$ value of .05 (in either direction) is expected by chance.

To ensure that the absence of complementarity was not an artifact of the quadrant technique, we also calculated Spearman rank correlations between morphological and phenological overlaps for all comparisons reported in Table 2 . Negative correlation coefficients would indicate a trade-off between displacement in time and displacement in morphology. Results, however, closely paralleled those reported in Table 2 : most correlations were close to zero or were positive, two ( $\mathrm{Hel}$ iconia tortuosa and Guzmania nicaraguensis) were significantly positive, and none was significantly negative.

\section{DISCUSSION}

Within a stable assemblage of plants, consistent competition for pollination may result in nonrandom patterns among the species' flowering phenologies or floral morphologies, provided that no other constraints on those traits exist (Feinsinger 1983, Waser 1983, Rathcke and Lacey 1985). Character displacement leading to decreased phenological or morphological overlap could result from either (1) natural selection within the community against phenotypes with flowering seasons or morphologies that overlap those of other guildmates (e.g., Waser 1978a), or (2) selective establishment in the community of species with dissimilar phenologies and morphologies (e.g., Feinsinger 1978, 1983, Waser 1978a, Primack 1985). Pollination in the Monteverde cloud forest is often insufficient for maximum seed set and clearly relates to plant fitness (Feinsinger et al. 1986); W. H. Busby and S. Kinsman (personal observation) surveyed most species listed in Table 1 and found that many flowers received fewer compatible pollen grains than the number of ovules available for fertilization. In this study, we fully expected at least the short-flower hummingbird pollination guild, which has relatively little opportunity for morphological displacement (Feinsinger et al. 1986), to demonstrate displaced flowering phenologies. We expected the long-flower guild, which has much more opportunity for morphological displacement (Feinsinger et al. 1986), to demonstrate complementarity between phenological and morphological displacement. Indeed, even phenological convergence is possible among rare species with widely different morphologies (Feinsinger 1983). Yet neither the randomization analysis of phenologies alone nor the tests for complementarity revealed the expected patterns. Furthermore, among short-flowered plants no relationship existed between rarity and phenological convergence, while among long-flowered plants increasingly rare species flowered in increasingly divergent, not convergent, patterns.

In some animal pollination guilds, failure of plants to exhibit phenological regularity has been attributed to constraints imposed by climatic seasonality (e.g., Schemske et al. 1978, Stiles 1979, Cole 1981, Motten 1986) or seasonal variation in pollinator availability (e.g., Waser 1979, Rathcke and Lacey 1985). Neither of these constraints appears to operate in the Monteverde cloud forest. Unlike second-growth tropical habitats (Colwell 1973, Feinsinger 1976, Wolf et al. 1976, Feinsinger et al. 1985) or forest canopy (Feinsinger and Colwell 1978), the cloud forest understory does not 
TABLE 1. Results of phenological overlap simulations for the two guilds of hummingbird-pollinated plants in the Monteverde cloud forest, based on 2 yr of data. Values reported are the percentage of cases in which the observed overlap between a particular species' flowering phenology and that of all other guildmates was greater than that obtained when all species' phenologies were scrambled randomly in time. Values $<5$ indicate lower overlap of actual flowering seasons than expected under the null hypothesis of randomly placed flowering seasons, those $>95$ indicate greater than expected overlap.

\begin{tabular}{|c|c|c|c|c|}
\hline \multirow[b]{2}{*}{ Species } & \multicolumn{2}{|c|}{$\begin{array}{c}\text { Data from study plots } \\
\text { only }\end{array}$} & \multicolumn{2}{|c|}{$\begin{array}{c}\text { Data from study plots } \\
\text { and belt transects }\end{array}$} \\
\hline & $\begin{array}{l}\text { Proportional } \\
\text { similarity } \\
\text { index }\end{array}$ & $\begin{array}{l}\text { Levins' } \\
\text { (1968) } \\
\text { index }\end{array}$ & $\begin{array}{l}\text { Proportional } \\
\text { similarity } \\
\text { index }\end{array}$ & $\begin{array}{l}\text { Levins' } \\
\text { (1968) } \\
\text { index }\end{array}$ \\
\hline
\end{tabular}

A. Flowers visited primarily by long-billed hummingbirds

Acanthaceae

Justicia aurea Schldl.

Poikilacanthus macranthus Lindau

Razisea spicata Oersted

$\begin{array}{ll}73 & 92 \\ 94 & 99\end{array}$

92

99
68

74

95

91

44

Bromeliaceae

Guzmania nicaraguensis Mez \& C. F. Baker ex Mez*

Pitcairnia brittoniana $\mathrm{Mez}^{*}$

3

3

Ericaceae

Psammisia ramiflora Klotsch

16

54

4

10

Gesneriaceae

Alloplectus tetragonus (Oerst.) Hanst.

Capanea grandiflora (Kunth) Decne ex Pl.*

Columnea magnifica Oersted

Columnea microcalyx Hanstein

Columnea lepidocaula Hanstein

Drymonia conchocalyx Hanstein

Drymonia rubra Morton

Heliconiaceae

Heliconia tortuosa Grigg

Lobeliaceae

Centropogon solanifolius Benth.

Malvaceae

Malvaviscus palmanus Pittier \& Donnell-Smith

Ravnia triflora Oerst.

$$
9
$$

61

100

Zingiberaceae

Costus barbatus Suess.

Renealmia thyrsoidea (R. \& P.) Poepp. et Endl.

B. Flowers visited primarily by short-billed hummingbirds

Acanthaceae

Hansteinia blepharorachis (Leonard) Durkee Dicliptera trifurca Oersted

Bromeliaceae

Guzmania nicaraguensis Mez \& C. F. Baker ex Mez*

Ericaceae

Cavendishia complectans Hemsley

Cavendishia crassifolia (Benth.) Hemsley

Gonocalyx pterocarpus (Donn. Sm.) Luteyn

Satyria warscewiczii Klotsch

Gesneriaceae

Besleria formosa Morton

Besleria princeps Hanst.

Besleria triflora (Oerst.) Hanst.

Lobeliaceae

Burmeistera tenuiflora Donn. Sm. 
TABLE 1. Continued.

\begin{tabular}{|c|c|c|c|c|}
\hline \multirow[b]{2}{*}{ Species } & \multicolumn{2}{|c|}{$\begin{array}{l}\text { Data from study plots } \\
\text { only }\end{array}$} & \multicolumn{2}{|c|}{$\begin{array}{l}\text { Data from study plots } \\
\text { and belt transects }\end{array}$} \\
\hline & $\begin{array}{l}\text { Proportional } \\
\text { similarity } \\
\text { index }\end{array}$ & $\begin{array}{l}\text { Levins' } \\
\text { (1968) } \\
\text { index }\end{array}$ & $\begin{array}{l}\text { Proportional } \\
\text { similarity } \\
\text { index }\end{array}$ & $\begin{array}{l}\text { Levins' } \\
(1968) \\
\text { index }\end{array}$ \\
\hline \multicolumn{5}{|l|}{ Rubiaceae } \\
\hline $\begin{array}{l}\text { Cephaelis elata Sw. } \\
\text { Palicourea lasiorrachis Benth. ex Oerst. } \\
\text { Palicourea macrocalyx Standl. }\end{array}$ & $\begin{array}{l}30 \\
71 \\
12\end{array}$ & $\begin{array}{r}28 \\
77 \\
8\end{array}$ & $\begin{array}{r}16 \\
64 \\
6\end{array}$ & $\begin{array}{r}19 \\
70 \\
6\end{array}$ \\
\hline
\end{tabular}

* Denotes species (Guzmania, Pitcairnia) whose pollen is carried primarily by long-billed hummingbirds, but sometimes by short-billed hummingbirds as well, or species (Capanea) whose pollen is carried primarily by short-billed hummingbirds but also by long-billed hummingbirds.

experience seasonal influxes of migrant hummingbirds (P. Feinsinger et al., personal observation). The major hummingbird pollinators (Lampornis calolaema and Phaethornis guy) are nonmigratory, and the population densities vary astonishingly little over the year (P. Feinsinger, W. H. Busby, and K. G. Murray, personal $o b$ servation). At various times of the year, bursts of flowering in canopy Ericaceae occasion sudden declines in visit frequencies of Lampornis to understory flowers, but these dips are of short duration and are unpredictable in timing (W. H. Busby, personal observation). Furthermore, we could discern no climatic constraints on flowering seasons. Both the driest and wettest seasons are characterized by intense flowering of several species from both guilds (Linhart et al., in press). Although there is somewhat of a lull in production of short flowers fiom August through October, and in long flowers from May through August (Feinsinger et al. 1986: Fig. 3), these periods are not clearly related to climatic constraints.

Phylogeny may broadly constrain flowering phenologies of cloud forest plants to certain seasons, a pattern also noted in temperate floras (Kochmer and Handel 1986). For example, Acanthaceae listed in Table 1 flower primarily from late wet season to early dry season (September-March), Gesneriaceae flower primarily from early dry season through early wet season (November-Iune), and Rubiaceae flower primarily from mid dry season through mid wet season (MarchSeptember). Furthermore, related species elsewhere in Costa Rica and even in Trinidad and Tobago tend to flower within the same periods (cf. Stiles 1978, 1985, Feinsinger et al. 1982). Nevertheless, within these constraints natural selection due to competition could still adjust phenologies (or morphologies) to minimize overlap (Waser 1978a, 1979, 1983), and selective establishment of species from a phylogenetically diverse pool could lead to a complementary set of species, regardless of phylogenetic origins (Primack 1985, Kochmer and Handel 1986). Thus phylogenetic constraints, while restricting lability in flowering phenology and morphology of particular species (cf. Kochmer and Handel 1986), cannot alone account for the absence of pattern among the phylogenetically diverse guilds examined here.

Could selection for optimal timing of fruit and seed maturation override the expected selective forces on flowering phenologies, and thus be responsible for scarcity of pattern in the latter? Rathcke and Lacey (1985) point out that timing of fruit maturation, seed dispersal, and germination may be more critical to plant fitness than timing of flowering. Murray (1986) has shown that seasonal migrations of some frugivorous birds at Monteverde affect the rate of fruit removal from plants depending on them for seed dispersal, making some seasons better than others for fruit maturation. However, although most of the plants listed in Table 1 are adapted for seed dispersal by birds (Wheelwright et al. 1984), most are dispersed by nonmigratory as well as migratory species. Hence seasonal variation in dispersal success is probably minimal in most species. Furthermore, although early wet season may be optimal with respect to germination and seedling survival in some communities (e.g., Garwood 1983), data currently available suggest that timing of flowering and fruiting are not strongly interdependent (Rathcke and Lacey 1985, Skeate 1985). Thus, strong selective forces on fruiting phenology, even if they exist, need not affect flowering phenology. Also, even if seasonal constraints on fruiting and seed dispersal affected flowering phenologies, they would not explain the absence of a complementary relationship between flowering phenology and morphology (Table 2).

Having exhausted alternative explanations for the apparent lack of expected patterns in flowering phenology and floral morphology, we must turn to the premise of the process-and-pattern argument: that competition for pollination occurs consistently within a stable assemblage of plants. We suggest that neither consistent competition nor long-term stability characterizes many plant assemblages. Although competitive mechanisms certainly exist among the plant species considered here (P. Feinsinger, W. H. Busby, and H. M. Tiebout III, personal observation), other work at 


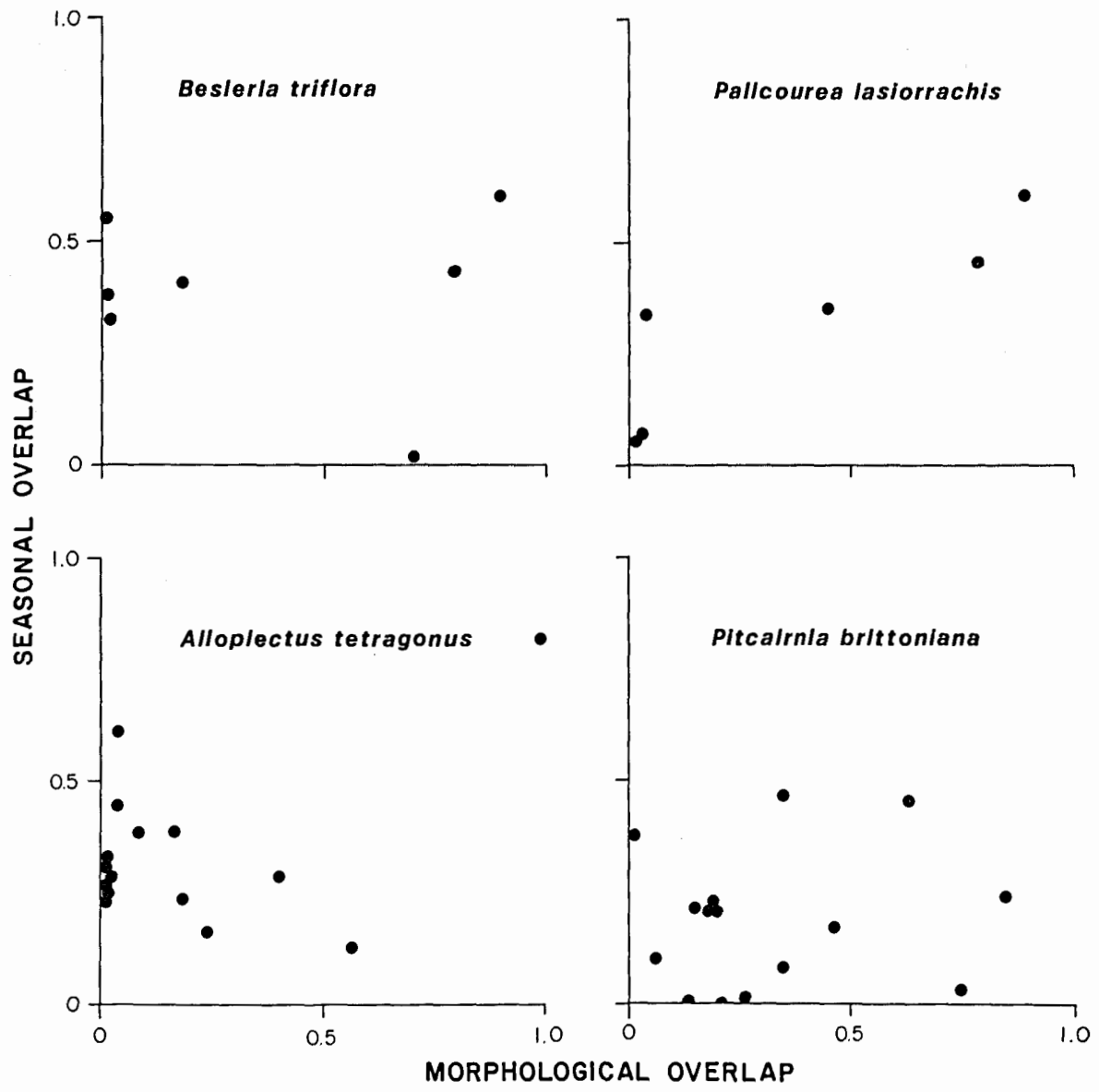

FIG. 2. Observed relationships between phenological overlap (measured with Eq. 1) and morphological overlap (Eq. 3) for four typical hummingbird-pollinated plant species from the Monteverde cloud forest. Each point represents the overlaps between the indicated species and one other species in the same guild.

Monteverde (Feinsinger et al. 1986) suggests that the expression of these mechanisms in the field may be quite sporadic. During 1982-1983, we examined the relationship between a plant's pollination success (defined as the number of conspecific, compatible pollen grains received by its stigmas) and the species composition of neighboring flowers. Among the four species examined (long-flowered Razisea spicata and Drymonia rubra, and short-flowered Hansteinia blepharorachis and Besleria triflora), we found evidence for negative density dependence only in the two shortflowered species, and even then only sporadically. Besleria did experience pronounced competitive effects at the ends of its flowering season, but not during its peak. The opposite was true for Hansteinia. Neither longflowered species experienced negative density-dependent effects from other species during any of the three seasonal samples. In fact, one sample for each longflowered species suggested that interspecific facilitation (Rathcke 1983, Thomson 1983), rather than competition, occurred regardless of the morphological simi- larity of neighbors. Thus, the reproductive consequences of flowering at the "wrong" time, or of having a morphology similar to that of neighbors, are not at all clear-cut.

In addition, the nature of interspecific interactions undoubtedly varies between years, as well as within years. Flowering phenologies of the plants we examined, like phenologies of other animal-pollinated plants (Stiles 1977, Rathcke and Lacey 1985), varied quite extensively and independently among the four years for which we now have data (Y. B. Linhart et al., personal observation). Thus, each year a given plenotype is likely to face a quite different array of interacting species (cf. Rathcke and Lacey 1985). Such temporally variable competitive environments permit the coexistence of species (or phenotypes) having traits that would be suboptimal in a stable environment (Chesson 1986, Chesson and Case 1986, Hubbell and Foster 1986).

Furthermore, the species composition of plant assemblages may not be sufficiently stable in time or space for competition, even if it were consistent, to sort 
TABLE 2. Relationship between phenological overlap between species pairs, calculated as proportional similarity in distribution of flowering over time (Eq. 1), and morphological overlap in terms of anther placement (Eq. 3).

\begin{tabular}{|c|c|c|}
\hline Species* & $\begin{array}{c}\text { Number of } \\
\text { pairs in } \\
\text { upper-right } \\
\text { quadrant } \dagger \\
\text { (high overlap } \\
\text { on both axes) }\end{array}$ & $\begin{array}{l}\text { Result of } \\
\text { corner test }\end{array}$ \\
\hline \multicolumn{3}{|c|}{ Long-flowered guild } \\
\hline \multicolumn{3}{|l|}{ Acanthaceae } \\
\hline Justicia aurea & 3 & NS \\
\hline Poikilacanthus macranthus & 3 & NS \\
\hline Razisea spicata & 4 & NS \\
\hline \multicolumn{3}{|l|}{ Bromeliaceae } \\
\hline Guzmania nicaraguensis & 5 & NS \\
\hline Pitcairnia brittoniana & 3 & NS \\
\hline \multicolumn{3}{|l|}{ Ericaceae } \\
\hline Psammisia ramiflora & 4 & NS \\
\hline \multicolumn{3}{|l|}{ Gesneriaceae } \\
\hline Alloplectus tetragonus & 4 & NS \\
\hline Columnea microcalyx & 3 & NS \\
\hline Columnea magnifica & 6 & $P<.01 \ddagger$ \\
\hline Drymonia conchocalyx & 3 & NS \\
\hline Drymonia rubra & 3 & NS \\
\hline \multicolumn{3}{|l|}{ Heliconiaceae } \\
\hline Heliconia tortuosa & 6 & $P<.005 \ddagger$ \\
\hline \multicolumn{3}{|l|}{ Lobeliaccae } \\
\hline Centropogon solanifolius & 3 & NS \\
\hline \multicolumn{3}{|l|}{ Malvaceae } \\
\hline Malvaviscus palmanus & 2 & $P<.05 \S$ \\
\hline \multicolumn{3}{|l|}{ Rubiaceae } \\
\hline Ravnia triflora & 4 & NS \\
\hline \multicolumn{3}{|l|}{ Zingibericeae } \\
\hline Costus barbatus & 4 & NS \\
\hline All long-tlowered species pairs & 29 & NS \\
\hline \multicolumn{3}{|c|}{ Short-flowered guild $\|$} \\
\hline \multicolumn{3}{|l|}{ Acanthaceae } \\
\hline Diclipiera trifurca & 2 & \\
\hline Hansteinia blepharorachis & 1 & \\
\hline \multicolumn{3}{|l|}{ Gesneriaceae } \\
\hline Besleria triflora & 2 & \\
\hline Besleria formosa & 2 & \\
\hline \multicolumn{3}{|l|}{ Lobeliaccae } \\
\hline Burmeistera tenuiflora & 2 & \\
\hline \multicolumn{3}{|l|}{ Rubiaceac } \\
\hline Cephaelis elata & 2 & \\
\hline Palicourea lasiorrachis & 2 & \\
\hline Palicourea macrocalyx & 1 & \\
\hline All short-flowered species pairs & 9 & NS \\
\hline
\end{tabular}

* The Jist is smaller than that in Table 1 because complete morphological data could not be obtained for all species.

†Quadrants were determined by the method used for the corner test of association (Steele and Torrie 1960:410). After pairs deleted by quadrant method, total pairs for each species of long-flowered plant are $14 ; 6$ for each short-flowered plant; 120 total long-flowered pairs; 28 total short-flowered pairs.

$\ddagger$ More pairs than expected in upper right, counter to hypothesis.

$\S$ Fewer pairs in upper right than expected.

|| Number of pairs too few for corner test of association.

phenologies into a precise pattern. (1) Ranges of the species making up each guild do not coincide even within the Monteverde cloud forest; thus, each population interacts with an assemblage of guildmates whose species composition changes rapidly over space. (2) Davis (1986) provides evidence that rates of plant migration in eastern North America are species-specific and often very rapid in geological time, and there is no reason to expect markedly greater stability in Central American forests. Unless diffuse competition from extant species is sufficiently strong to prevent any sexual reproduction from occurring in a recent colonist population, the reshuffling of populations at any one site may simply be too rapid to allow the formation of pattern, whether by natural selection among co-occurring species, or by differential establishment success based on floral traits (see Colwell and Winkler 1984).

\section{ACKNOWLEDGMENTS}

We especially thank C. Guindon, W. Z. Pounds, and J. A. Wolfe for helping to collect the data. Facilities and assistance were provided by $\mathrm{W}$. Guindon and other personnel of the Monteverde Cloud Forest Reserve, operated by Tropical Science Center. W. Judd, K. Perkins, and D. Hall (University of Florida), W. Burger and P. Matekaitis (Field Museum), G. Davidse and R. E. Gereau (Missouri Botanical Garden), J. Luteyn (New York Botanical Garden), L. Skog (U.S. National Museum), and L. H. Durkee (Grinnell College) determined plants. C. Martinez del Rio came up with Equation 3, and Jorge Soberon suggested using the quadrant technique. T. H. Fleming, D. W. Inouye, D. R. Strong Jr., J. D. Thomson, and N. M. Waser commented on earlier drafts. The study was supported by NSF grants DEB 80-11008 to P. Feinsinger and DEB 80-11023 to Y. B. Linhart.

\section{Literature Cited}

Bawa, K. S. 1983. Patterns of flowering in tropical plants. Pages 394-410 in C. E. Jones and R. J. Little, editors. Handbook of experimental pollination biology. Van Nostrand Reinhold, New York, New York, USA.

Brown, J. H., and A. Kodric-Brown. 1979. Convergence, competition, and mimicry in a temperate community of hummingbird-pollinated flowers. Ecology 60:1022-1035.

Chesson, P. L. 1986. Environmental variation and the coexistence of species. Pages 240-256 in J. Diamond and T. J. Case, editors. Community ecology. Harper and Row, New York, New York, USA.

Chesson, P. L., and T. J. Case. 1986. Overview: nonequilibrium community theories: chance, variability, history, and coexistence. Pages 229-239 in J. Diamond and T. J. Case, editors. Community ecology. Harper and Row, New York, New York, USA.

Cole, B. J. 1981. Overlap, regularity, and flowering phenologies. American Naturalist 117:993-997.

Colwell, R. K. 1973. Competition and coexistence in a simple tropical community. American Naturalist 107:737-760.

Colwell, R. K., and D. W. Winkler. 1984. A null model for null models in biogeography. Pages 344-359 in D. R. Strong, Jr., D. Simberloff, L. G. Abele, and A. B. Thistle, editors. Ecological communities: conceptual issues and the evidence. Princeton University Press, Princeton, New Jersey, USA.

Connell, J. H. 1983. On the prevalence and relative importance of interspecific competition: evidence from field experiments. American Naturalist 122:661-696.

Davis, M. B. 1986. Climatic instability, time lags, and community disequilibrium. Pages 269-284 in J. Diamond and T. J. Case, editors. Community ecology. Harper and Row, New York, New York, USA.

Diamond, J., and T. J. Case, editors. 1986. Community ecology. Harper and Row, New York, New York, USA. 
Feinsinger, P. 1976. Organization of a tropical guild of nectarivorous birds. Ecological Monographs 46:257-291.

1978. Ecological interactions between plants and hummingbirds in a successional tropical community. Ecological Monographs 48:269-287.

in D. J. Futuyma and M. Slatkin, editors. Coevolution. Sinauer, Sunderland, Massachusetts, USA.

Feinsinger, P., J. H. Beach, Y. B. Linhart, W. H. Busby, and K. G. Murray. 1987. Disturbance, pollinator predictability, and pollination success among Costa Rican cloud forest plants. Ecology 68:1294-1305.

Feinsinger, P., and R. K. Colwell. 1978. Community organization among neotropical nectar-feeding birds. American Zoologist 18:779-795.

Feinsinger, P., K. G. Murray, S. Kinsman, and W. H. Busby. 1986. Floral neighborhood and pollination success in four hummingbird-pollinated cloud forest plants. Ecology 67: 449-465.

Feinsinger, P., L. A. Swarm, and J. A. Wolfe. 1985. Nectarfeeding birds on Trinidad and Tobago: comparison of diverse and depauperate guilds. Ecological Monographs 55: 1-28.

Feinsinger, P., J. A. Wolfe, and L. A. Swarm. 1982. Island ecology: reduced hummingbird diversity and the pollination biology of plants on Trinidad and Tobago, West Indies. Ecology 63:494-506.

Fleming, T. H. 1985. Coexistence of five sympatric Piper (Piperaceae) species in a tropical dry forest. Ecology 66: 688-700.

Fleming, T. H., and B. L. Partridge. 1984. On the analysis of phenological overlap. Oecologia (Berlin) 62:344-350.

Garwood, N. C. 1983. Seed germination in a seasonal tropical forest in Panama: a community study. Ecological Monographs 53:159-181.

Gentry, A. H. 1974. Flowering phenology and diversity in tropical Bignoniaceae. Biotropica 6:64-68.

Gleeson, S. K. 1981. Character displacement in flowering phenologies. Oecologia (Berlin) 51:294-295.

Harvey, P. H., R. K. Colwell, J. V. Silvertown, and R. M. May. 1983. Null models in ecology. Annual Review of Ecology and Systematics 14:189-211.

Heinrich, B. 1975. Bee flowers: a hypothesis on flower variety and blooming times. Evolution 29:325-334.

Heithaus, E. R. 1974. The role of plant-pollinator interactions in determining community structure. Annals of the Missouri Botanical Garden 61:675-691.

Holdridge, L. R. 1967. Life zone ecology. Tropical Science Center, San Jose, Costa Rica.

Hubbell, S. P., and R. B. Foster. 1986. Biology, chance, and history and the structure of tropical rain forest tree communities. Pages 314-329 in J. Diamond and T. J. Case, editors. Community ecology. Harper and Row, New York, New York, USA.

Kochmer, J. P., and S. N. Handel. 1986. Constraints and competition in the evolution of flowering phenology. Ecological Monographs 56:303-325.

Lawton, R., and V. Dryer. 1980. The vegetation of the Monteverde Cloud Forest Reserve. Brenesia 18:101-116.

Levins, R. 1968. Evolution in changing environments. Princeton University Press, Princeton, New Jersey, USA.

Linhart, Y. B., P. Feinsinger, J. H. Beach, W. H. Busby, K. G. Murray, W. Z. Pounds, S. Kinsman, C. A. Guindon, and M. Kooiman. 1987. Disturbance and predictability of flowering patterns in bird-pollinated cloud forest plants. Ecology, in press.

MacArthur, R. H. 1972. Geographical ecology. Harper and Row, New York, New York, USA.

Motten, A. F. 1986. Pollination ecology of the spring wild- flower community of a temperate deciduous forest. Ecological Monographs 56:21-42.

Murray, K. G. 1986. Avian seed dispersal of neotropical gap-dependent plants. Dissertation. University of Florida, Gainesville, Florida, USA.

Parrish, J. A. D., and F. A. Bazzaz. 1979. Difference in pollination niche relationships in early and late successional plant communities. Ecology 60:597-610.

Pianka, E. R. 1974. Niche overlap and diffuse competition. Proceedings of the National Academy of Sciences, (USA) 71:2141-2145.

Pleasants, J. M. 1980. Competition for bumblebees in Rocky Mountain plant communities. Ecology 61:1446-1459.

- 1983. Structure of plant and pollinator communities. Pages 375-393 in C. E. Jones and R. J. Little, editors. Handbook of experimental pollination biology. Van Nostrand Reinhold, New York, New York, USA.

Poole, R. W., and B. J. Rathcke. 1979. Regularity, randomness, and aggregation in flowering phenologies. Science 203: 470-471.

Primack, R. B. 1985. Patterns of flowering phenology in communities, populations, individuals, and single flowers. Pages 571-593 in J. White, editor. The population structure of vegetation. W. Junk, Dordrecht, The Netherlands.

Rabinowitz, D., J. K. Rapp, V. L. Sork, B. J. Rathcke, G. A. Reese, and J. C. Weaver. 1981. Phenological properties of wind- and insect-pollinated prairie plants. Ecology 62: 49-56.

Rathcke, B. J. 1983. Competition and facilitation among plants for pollination. Pages 305-329 in L. A. Real, editor. Pollination biology. Academic Press, New York, New York, USA.

Rathcke, B. J., and E. P. Lacey. 1985. Phenological patterns of terrestrial plants. Annual Review of Ecology and Systematics 16:179-214.

Root, R. B. 1967. The niche exploitation pattern of the bluegray gnatcatcher. Ecological Monographs 37:317--350.

Schemske, D. W., M. F. Willson, M. N. Melampy, L. J. Miller, L. Verner, K. M. Schemske, and L. B. Best. 1978. Flowering ecology of some spring woodland herbs. Ecology 59: $351-366$.

Schoener, T. W. 1983. Field experiments on interspecific competition. American Naturalist 122:240-285.

- 1986. Overview: kinds of ecological communitiesecology becomes pluralistic. Pages 467-479 in J. Diamond and T. J. Case, editors. Community ecology. Harper and Row, New York, New York, USA.

Simberloff, D. 1983. Sizes of coexisting species. Pages 404430 in D. J. Futuyma and M. Slatkin, editors. Coevolution. Sinauer, Sunderland, Massachusetts, USA.

Skeate, S. 1985. Mutualistic interactions between birds and fruits in a northern Florida hammock community. Dissertation. University of Florida, Gainesville, Florida, USA.

Steele, R. G. D., and J. H. Torrie. 1960. Principles and procedures of statistics. McGraw-Hill, New York, New York, USA.

Stiles, F. G. 1975. Ecology, flowering phenology, and hummingbird pollination of some Costa Rican Heliconia species. Ecology 56:285-301.

- 1977 . Coadapted competitors: the flowering seasons of hummingbird-pollinated plants in a tropical forest. Science 198:1177-1178.

- 1978. Temporal organization of flowering among the hummingbird food-plants of a tropical wet forest. Biotropica 10:194-210.

. 1979. Reply to Poole and Rathckc. Science 203: 471.

- 1981. Geographical aspects of the bird-flower c0evolution, with particular reference to Central America. Annals of the Missouri Botanical Garden 68:323-351. 
1985. Seasonal patterns and coevolution in the hummingbird-flower community of a Costa Rican subtropical forest. Pages 757-787 in P. A. Buckley, M. S. Foster, E. S. Morton, R. S. Ridgely, and F. G. Buckley, editors. Neotropical ornithology. Ornithological Monograph Number 36, American Ornithologists' Union, Lawrence, Kansas, USA.

Strong, D. R., Jr., D. Simberloff, L. G. Abele, and A. B. Thistle. 1984. Ecological communities: conceptual issues and the evidence. Princeton University Press, Princeton, New Jersey, USA.

Thomson, J. D. 1980. Skewed flowering distributions and pollinator attraction. Ecology 61:572-579.

1981. Spatial and temporal components of resource assessment by flower-feeding insects. Journal of Animal Ecology 50:49-60.

12. 1983. Component analysis of community-level interactions in pollination systems. Pages $451-460$ in C. E. Jones and R. J. Little, editors. Handbook of experimental pollination biology. Van Nostrand Reinhold, New York, New York, USA.

Thomson, J. D., and K. A. Rusterholz. 1982. Overlap summary indices and the detection of community structure. Ecology 63:274-277.

Waser, N. M. 1978a. Competition for hummingbird pollination and sequential flowering in two Colorado wildflowers. Ecology 59:934-944.
- $1978 b$. Interspecific pollen transfer and competition between co-occurring plant species. Oecologia (Berlin) 36: 223-236.

- 1979. Pollinator availability as a determinant of flowering time in ocotillo (Fouqueria splendens). Oecologia (Berlin) 39:107-121.

- 1983. Competition for pollination and floral character difference among sympatric plant species: a review of evidence. Pages 277-293 in C. E. Jones and R. J. Little, editors. Handbook of experimental pollination biology. Van Nostrand Reinhold, New York, New York, USA.

Waser, N. M., and L. A. Real. 1979. Effective mutualism between sequentially flowering plant species. Nature 281: 670-672.

Wheelwright, N. T. 1985. Competition for dispersers, and the timing of flowering and fruiting in a guild of tropical trees. Oikos 44:465-477.

Wheelwright, N. T., W. A. Haber, K. G. Murray, and C. Guindon. 1984. Tropical fruit-eating birds and their food plants: a survey of a Costa Rican lower montane forest. Biotropica 16:173-192.

Wolf, L. L., F. G. Stiles, and F. R. Hainsworth. 1976. Ecological organization of a tropical, highland hummingbird community. Journal of Animal Ecology 45:349-379.

Zimmerman, M. 1984. Reproduction in Polemonium: a five year study of seed production and implication for competition for pollinator service. Oikos 42:225-228. 